\title{
Validation of the Arabic version of the binge eating scale and correlates of binge eating disorder among a sample of the Lebanese population
}

Rouba Karen Zeidan ${ }^{1,2,3+}$, Chadia Haddad ${ }^{4,5+}$, Rabih Hallit ${ }^{6}$, Marwan Akel ${ }^{2,7}$, Karl Honein ${ }^{6}$, Maria Akiki ${ }^{6}$, Nelly Kheir ${ }^{8}$, Souheil Hallit ${ }^{2,6^{*}+}$ (D) and Sahar Obeid ${ }^{2,4,9^{*+}+}$

\begin{abstract}
Objectives: To test the psychometric properties of the Arabic version of the Binge Eating Scale (BES), a selfquestionnaire assessing binge eating, in a sample of the Lebanese population. The secondary objective was to evaluate factors associated with binge eating.

Methods: This cross-sectional study, conducted between January and May 2018, enrolled 811 adult participants from all districts of Lebanon. The BES was administered to study its psychometric properties. The sample was divided into two separate samples (405 for sample 1 and 406 for sample 2). An exploratory factor analysis was executed on Sample 1, followed by a confirmatory factor analysis on Sample 2 using the structure obtained in Sample 1. Three hierarchical stepwise linear regressions were conducted to assess factors associated with binge eating.
\end{abstract}

Results: The factor analysis suggested a two-factor structure for the BES explaining a total of $41.4 \%$ of the variance. All items could be extracted from the list. The internal consistency of the measurement was adequate (Cronbach's alpha $=0.86$ ). The confirmatory factor analysis revealed an adequate fit to the model with satisfactory Maximum Likelihood Chi-Square/Degrees of Freedom ( $x^{2} / \mathrm{df}$ ), Steiger-Lind RMSEA, Joreskog GFI, and AGFI. Higher BMI, depression, anxiety, emotional eating, greater body dissatisfaction, and more pressure from media to lose weight were associated with higher binge eating. Higher expressive suppression facet score was associated with lower binge eating.

Conclusion: The Arabic version of BES could be a useful tool for screening and assessing the binge eating behaviors in clinical practice and research. Also, being dissatisfied with one's body size, having a history of sexual abuse, family history of binge eating, increased depressive/anxiety symptoms, and lower self-esteem seem to be associated with higher BES scores.

Keywords: Binge eating disorder, Psychometrics properties, Depression, Body dissatisfaction, Emotions, Anxiety

\footnotetext{
*Correspondence: souheilhallit@hotmail.com; saharobeid23@hotmail.com

${ }^{\dagger}$ Rouba Karen Zeidan and Chadia Haddad are first co-authors.

${ }^{\dagger}$ Souheil Hallit and Sahar Obeid are last co-authors.

${ }^{2}$ INSPECT-LB: Institut National de Santé Publique, Epidemiologie Clinique et

Toxicologie, Beirut, Lebanon

Full list of author information is available at the end of the article
}

(c) The Author(s). 2019 Open Access This article is distributed under the terms of the Creative Commons Attribution 4.0 International License (http://creativecommons.org/licenses/by/4.0/), which permits unrestricted use, distribution, and reproduction in any medium, provided you give appropriate credit to the original author(s) and the source, provide a link to the Creative Commons license, and indicate if changes were made. The Creative Commons Public Domain Dedication waiver (http://creativecommons.org/publicdomain/zero/1.0/) applies to the data made available in this article, unless otherwise stated. 


\section{Plain English summary}

The Binge Eating Scale in its Arabic version is a suitable instrument to screen for binge eating among the Lebanese population. Some factors (body dissatisfaction, having a history of sexual abuse, a family history of binge eating, greater depressive/anxiety symptoms, and lower self-esteem) seem to be associated with higher binge eating.

\section{Introduction}

Binge eating disorder (BED) is an eating disorder (ED) characterized by recurrent episodes of binge eating (BE) without subsequent compensatory behaviors, such as self-induced vomiting or over-exercising [1]. Diagnosis of BED according to the Diagnostic and Statistical Manual of Mental Disorders, Fifth Edition (DSM-5), is based on the occurrence of at least one BE episode per week for three consecutive months; these episodes are characterized by the consumption of larger amounts of food in a short period when compared to the typical amounts for most people under similar circumstances, accompanied by a sense of loss of control over eating and a marked distress during these episodes [2]. A large study, pooling results from different community surveys done across 14 countries (high, upper-middle, and lowermiddle income countries), revealed an average lifetime prevalence estimate of $1.9 \%$ [0.2-4.7\%] for BED, making it the most common ED [3, 4]. Previous reviews showed that ED most frequently afflict young Western females within high-income and industrialized Western Europe and North America, but do also occur in diverse countries and cultures worldwide $[5,6]$. While there is a stabilization - even a lowering - of the incidence rates of eating disorders in Caucasian North American and Northern European groups, increased rates appear in Arab and Asian countries [7]. In fact, as Lebanon and other countries in the Middle Eastern and North African region continue to develop and undergo epidemiologic transition and cultural change, the burden of ED in these countries is rising $[8,9]$.

\section{Binge eating correlates}

The disorder was found to be more common in the population suffering from obesity [3], and it has been associated with several psychiatric (anxiety, depression, obsessive-compulsive disorder) and physical comorbidities (diabetes, hypertension) [3, 6, 10]. Previous findings showed that adverse childhood experiences (i.e. sexual/ physical abuse, other parental problems), parental depression, negative self-evaluation, vulnerability to obesity, and repeated exposure to negative comments about shape, weight, or eating were associated with BED. These findings support the hypothesis that risk factors associated with BED are similar to those with psychiatric disorders and obesity [11]. Furthermore, researchers have found BED to share characteristics with substance use and addictive disorders $[12,13]$. In addition to other similarities, BED and substance use can both be induced by stress and major life events, childhood trauma, neglect, and abuse [14-16].

\section{Arabic countries and Lebanon}

BED research remains limited in the Arab-speaking countries, despite overweight and obesity being important public health issues. Older studies done in Egypt [17, 18] first showed evidence for BE, without reporting any prevalence rates. Other findings revealed that $82 \%$ of females and $76 \%$ of males (mean age $=20$ years) had experienced at least one $\mathrm{BE}$ episode [19]. In Jordan, results showed that $16.9 \%$ of females (mean age $=13$ ) reported $\mathrm{BE}$ and $1.8 \%$ were considered as suffering from BED [20]. The prevalence of BE in Saudi Arabia females was $68.8 \%$ [21], whereas it ranged between 24 to $36 \%$ in the United Arabic Emirates [22].

In Lebanon, previous research revealed that $21.2 \%$ of one-university students were vulnerable to developing an ED, whereas $11.4 \%$ had already been diagnosed with an ED. The same paper showed that anxiety was the most important associated factor with ED, followed by stress, body image and depression [23]. Another Lebanese study published in 2017, done on patients suffering from ED and comparing BED to anorexia nervosa and bulimia nervosa, concluded that outpatients were mostly single, female, young adults coming from middle and high socio-economic backgrounds, suffering from severe ED symptoms and depression [24].

\section{The binge eating scale (BES)}

Due to the high prevalence of $\mathrm{BE}$, its comorbidities and outcomes, there was a need to establish instruments for its measurement. The BES, developed by Gormally et al. [25], is an interesting tool both in terms of evaluation and monitoring of these patients, because it can be used for the purposes of screening, evaluation of severity or monitoring of the disorder. The BES has been found to demonstrate a very good internal consistency (between 0.85 and 0.90$)$ and a good construct validity $[25,26]$.

The scale has previously been validated in many populations, including but not limited to, French [27], Italian [28], Spanish [29], Persian [30] and Malay [31]. The BES was found to have good validity and internal consistency in the original normative samples, consisting of overweight women seeking behavioral treatment for obesity [25]. A study done by Imperatori et al. that evaluated the dimensionality and psychometric properties of the Italian version of the BES had found that the scale had good internal consistency $(\alpha=0.89)$, with a moderate mean inter-item correlation [28]. A study done among a 
sample of 1008 women from the general population confirmed that the BES presents a one-dimensional factorial structure, with very good construct reliability and convergent validity, and with a very good retest reliability [32]. In the French version, one factor was obtained that explained $61 \%$ of the total variance [27]. Timmerman had also found a good test-retest reliability $r=0.87$ for the total BES score. However, its factor structure is still controversial. Although Gormally et al. originally proposed a two-dimensional structure, dividing the items into cognitive and behavioral $\mathrm{BE}$, results on its dimensionality are contradictory. In a Mexican [33] and a Malay study [31], results showed a two-factor structure through exploratory factor analyses; they also found the unidimensional structure to be relevant as well. A study done on Portuguese women found the BES to have a good fit for a one-factor structure using a confirmatory factor analysis [32]. This was also supported by a French study done in non-clinical and clinical samples using an exploratory factor analysis [27]. A recent Spanish study targeting a sample of Spanish college students reported that a one-factor model fit the data best [34].

To our knowledge, no publication has reported the validation and the psychometric properties of the BES in the Arabic-speaking population. In addition, there is a need for more evidence about the factor structure of the scale in non-clinical samples, because most research has tested the validity of BES in specific populations (sufferers of overweight/obesity and bariatric surgery patients). Also, no study has been previously done on the Lebanese general population in order to study BED and its correlates when compared to healthy individuals. Hence, the aim of this work was to test the psychometric properties of an Arabic version of the BES, by establishing the factorial structure, its internal consistency and its construct validity in a sample of the Lebanese population. Another objective was to study BED's associated sociodemographic and clinical factors.

\section{Methods}

\section{Participants}

This study was cross-sectional, conducted between January and May 2018. Out of 1000 distributed questionnaires, 811 (81.1\%) were completed and collected. Enrollment of participants was done using a proportionate random sample from all Lebanese Mohafazat (Beirut, Mount Lebanon, North, South and Bekaa). Each Mohafaza is divided into Caza (stratum). In each Caza, two villages were randomly selected from the list of villages provided by the Central Agency of Statistics in Lebanon. Participants were randomly selected from each village. In each selected village, the questionnaire was distributed randomly to the households, based on random sampling technique to select the included house. Houses were assigned identification numbers and randomized according to an online software, Research Randomizer (www.randomizer.org). All members in the household, if eligible, were invited to participate in the study; those who accepted our invitation were asked to fill out the questionnaire. The same methodology was used in previous papers [35-38].

Prior to participation, individual subjects were briefed on the study objectives and methodology, and were assured of the anonymity of their participation. Individuals agreeing to participate in the study were then asked to read through and sign off on a written, informed consent form. Individual participants had the right to accept or refuse participation in the study with no financial compensation provided in exchange for individual participation. All participants above 18 years of age were eligible to participate. Excluded participants were those suffering from a clinical mental impairment affecting cognition and their ability to comprehend participation in the study and/or their ability to answer the questionnaire. The sample was divided into two separate samples for the validation of the BES (Study 1: $n=406$ for the exploratory analysis; Study 2: $n=405$ for the confirmatory analysis; therefore, $406 / 16=25$ participants per item were included in study 1 and $405 / 16=25$ per item in study 2 as well). However, the whole sample $(n=811)$ was used to study the factors correlated with $\mathrm{BE}$.

The mean age of the participants in the first sample was $27.96 \pm 11.83$ years, with $67.6 \%$ females. The majority $(73.3 \%)$ had a university level of education, single (66.1\%), with a low monthly income (76.4\%). Almost all participants drank caffeine (90.5\%), 31.7\% were smokers and $3.1 \%$ were drank alcohol. The majority practice physical activities (63.6\%). More than half of the participants had normal weight (52.4\%), 27.2\% were overweight and only $11.1 \%$ suffered from obesity, with a mean BMI of $24.10 \pm 4.98 \mathrm{Kg} / \mathrm{m}^{2}$. The majority of the participants (82.8\%) had no binge eating, $15.9 \%$ had moderate BE and $1.3 \%$ had severe $\mathrm{BE}$.

In sample 2, the mean age of the participants was 27.19 years, $65.4 \%$ were females, $67.8 \%$ were single, and $79.2 \%$ had low monthly income. The majority had a university degree $(73.1 \%)$ and $61.3 \%$ practice physical activities. More than half of the participants had normal weight (53.8\%), 26.5\% had overweight and only $12.4 \%$ suffered from obesity, with a mean BMI of $24.60 \pm 5.55$. No significant difference was found between the two samples $(p>0.05)($ Table 1$)$.

\section{Minimal sample size calculation}

Comrey and Lee suggested that a minimum of 10 observations per item is necessary in order to avoid computational difficulties [39]. Since the BES questionnaire contains 16 questions, a minimal sample of 160 patients was needed to conduct an exploratory factor analysis. 
Table 1 Characteristics of the study sample

\begin{tabular}{|c|c|c|c|c|}
\hline & Total & Sample 1 & Sample 2 & $p-$ \\
\hline & Frequency (\%) & Frequency (\%) & Frequency (\%) & \\
\hline Gender & & & & \\
\hline Male & $270(33.5 \%)$ & $131(3.4 \%)$ & $139(34.6 \%)$ & 0.518 \\
\hline Female & $536(66.5 \%)$ & $273(67.6 \%)$ & $263(65.4 \%)$ & \\
\hline Marital status & & & & \\
\hline Single & $533(67.0 \%)$ & $263(66.1 \%)$ & $270(67.8 \%)$ & 0.395 \\
\hline Married & $230(28.9 \%)$ & $120(30.2 \%)$ & $110(27.6 \%)$ & \\
\hline Widowed & $11(1.4 \%)$ & $7(1.8 \%)$ & $4(1.0 \%)$ & \\
\hline Divorced & $22(2.8 \%)$ & $8(2.0 \%)$ & $14(3.5 \%)$ & \\
\hline Education level & & & & \\
\hline Primary & $24(3.1 \%)$ & $11(2.8 \%)$ & $13(3.3 \%)$ & 0.760 \\
\hline Complementary & $61(7.8 \%)$ & $34(8.7 \%)$ & $27(6.9 \%)$ & \\
\hline Secondary & $125(15.9 \%)$ & $60(15.3 \%)$ & 65 (16.6\%) & \\
\hline University & $574(73.2 \%)$ & $288(73.3 \%)$ & $286(73.1 \%)$ & \\
\hline Monthly income & & & & \\
\hline No income & $340(45.1 \%)$ & $168(44.4 \%)$ & $172(45.7 \%)$ & 0.140 \\
\hline$<1000$ USD & $247(32.8 \%)$ & $121(32.0 \%)$ & $126(33.5 \%)$ & \\
\hline 1000-2000 USD & $117(15.5 \%)$ & $56(14.8 \%)$ & $61(16.2 \%)$ & \\
\hline$>2000$ USD & $50(6.6 \%)$ & $33(8.37 \%)$ & $17(4.5 \%)$ & \\
\hline Smoking & & & & \\
\hline Yes & $246(30.8 \%)$ & $127(31.7 \%)$ & $119(29.8 \%)$ & 0.572 \\
\hline No & $554(69.2 \%)$ & $274(68.3 \%)$ & $280(70.2 \%)$ & \\
\hline Alcohol & & & & \\
\hline Yes & $32(4.2 \%)$ & $12(3.1 \%)$ & $20(5.4 \%)$ & 0.124 \\
\hline No & $724(95.8 \%)$ & $372(96.9 \%)$ & $352(94.6 \%)$ & \\
\hline Caffeinated beverag & & & & \\
\hline Yes & $721(90.0 \%)$ & $362(90.5 \%)$ & 359 (89.5\%) & 0.646 \\
\hline No & $80(10.0 \%)$ & $38(9.5 \%)$ & $42(10.5 \%)$ & \\
\hline Practicing sport acti & & & & \\
\hline Yes & $490(62.4 \%)$ & $248(63.6 \%)$ & $242(61.3 \%)$ & 0.501 \\
\hline No & $295(37.6 \%)$ & $142(36.4 \%)$ & $153(38.7 \%)$ & \\
\hline BMl categories & & & & \\
\hline Underweight & $65(8.3 \%)$ & $36(9.3 \%)$ & $29(7.3 \%)$ & 0.733 \\
\hline Normal & 417 (53.1\%) & $204(52.4 \%)$ & $213(53.8 \%)$ & \\
\hline Overweight & $211(26.9 \%)$ & $106(27.2 \%)$ & $105(26.5 \%)$ & \\
\hline Obese & $92(11.7 \%)$ & $43(11.1 \%)$ & 49 (12.4\%) & \\
\hline & Mean \pm SD & Mean \pm SD & Mean $\pm S D$ & \\
\hline Age (in years) & $27.59 \pm 11.76$ & $27.96 \pm 11.83$ & $27.19 \pm 11.68$ & 0.354 \\
\hline BMI $\left(\mathrm{Kg} / \mathrm{m}^{2}\right)$ & $24.35 \pm 5.28$ & $24.10 \pm 4.98$ & $24.60 \pm 5.55$ & 0.182 \\
\hline
\end{tabular}

\section{Procedure}

Data collection was performed through personal interviews with participants by trained clinical psychologists, independent of this study, who clinically evaluated the level of psychiatric illness to exclude those who have psychiatric problems.

\section{Materials}

The questionnaire used during the interview was in Arabic, the native language of Lebanon. The first part assessed the sociodemographic details and other characteristics of the participants (i.e. age, gender, monthly 
income, education level, details about alcohol and caffeine intake, drug addiction, smoking status, and the physical activity). The monthly income was divided into four levels: no income, low income < 1000 USD; intermediate income 1000-2000 USD; and high income > 2000 USD. Afterward, the monthly income was categorized in three groups: low (no income with income < 1000 USD), intermediate (1000-2000 USD) and high (> 2000 USD) income, since the majority of the participants were university students and they have no real income. The heights and weights of participants were measured to calculate the Body Mass Index (BMI) $\left(\mathrm{kg} / \mathrm{m}^{2}\right)$. The BMI was classified into four categories: underweight $(<$ $\left.18.5 \mathrm{~kg} / \mathrm{m}^{2}\right), \quad$ normal $\left(18.5 .24 .9 \mathrm{~kg} / \mathrm{m}^{2}\right), \quad$ overweight $\left(25.0 .29 .9 \mathrm{~kg} / \mathrm{m}^{2}\right)$, and obese $\left(30.0 \mathrm{~kg} / \mathrm{m}^{2}\right)$ [40]. The Total Physical Activity Index was calculated by multiplying the intensity, duration, and frequency of daily activity, with higher scores indicating better physical activity.

The second part of the questionnaire consisted of behavioral practices of certain eating habits among participants. Questions about eating disorders were identified from previous articles [41-43]. Questions included: "Do you take your weight daily?", "Do you follow a diet to lose weight?", "Do you exercise to lose weight?", "Do you take diet pills to lose weight?", "Do you take laxatives or vomit to lose weight?", "Do you starve yourself to lose weight?"

\section{Binge eating scale (BES)}

The BES was originally developed to identify participants with binge eating within people suffering from obesity [25]. It does not specify a time frame and presents a series of differently weighted statements for each item, from which respondents select the statement that best describes their attitudes and behaviors. This yields a continuous measure of BE pathology of 0-46. Scores of $\geq 27$ have conventionally served as a cutoff value for identifying the presence of severe $\mathrm{BE}$ and 17 as a cutoff value for mild or no BE [44]. The BES has good testretest reliability $(\mathrm{r}=0.87, p<0.001)$. The Arabic version can be found at the end of this manuscript (Additional file 1: Appendix 1).

\section{Body dissatisfaction subscale of the eating disorder inventory-second version (EDI-2)}

In the present study, the body dissatisfaction score was measured from the eating disorder inventory (EDI-2) subscale since the body dissatisfaction could cause restraint eating which in turn causes susceptibility to loss of control over eating. The scale assesses the levels of dissatisfaction with the overall body shape and specific body parts. The body dissatisfaction subscale consists of nine items, measured in 4-point Likert scales, ranging from 0 (sometimes, rarely, never) to 3 (always). Five questions were reversed while doing the score calculation. The total score was calculated by summing the nine items. The total score ranged from 0 to 27. Higher scores are indicative of greater body dissatisfaction [45]. In this study, the Cronbach's alpha was 0.779 .

\section{Self-esteem scale}

The Rosenberg Self-Esteem10-item scale is used to assess beliefs and attitudes regarding general self-worth by using 4-point scales ranging from 1 (strongly disagree) to 4 (strongly agree). Five questions $(3,5,8,9$, and 10) were reversed while doing the score calculation. Higher scores indicated a more negative self-esteem [41]. In this study, the Cronbach's alpha was 0.759 .

\section{Perceived stress scale (PSS)}

The questions in the PSS ask about feelings and thoughts during the last month [42]. The PSS is a tenitem scale with answers ranging from never $(0)$ to almost always (4). Items $4,5,7$, and 8 are reversed items. The total score is calculated by summing the 10 items with higher scores indicating more perceived stress [42]. In this study, the Cronbach's alpha was 0.709.

\section{HAM-A scale}

The Hamilton Anxiety Rating Scale (HAM-A), recently validated in Lebanon [43], consists of 14 symptom-defined elements, and targets both psychological and somatic symptoms. Each item is scored on a basic numeric scoring of 0 (not present) to 4 (severe). Higher scores indicating higher anxiety. In this study, the Cronbach alpha's was 0.912. The Arabic version can be found at the end of this manuscript (Additional file 1: Appendix 2).

\section{HAM-D scale}

The Hamilton Scale for Depression (HAM-D), validated in Lebanon [46], is a multiple item questionnaire used to provide an indication of the severity of depression and is widely used in research. The 17 -item version was used in this study, with each item rated on either a 3- or 5-point scale and summed to obtain the total score. Higher scores indicated higher depression. In this study, the Cronbach's alpha was 0.879 . The Arabic version can be found at the end of this manuscript (Additional file 1: Appendix 3).

\section{Emotion regulation questionnaire (ERQ)}

The ERQ is used to measure respondents' tendency to regulate their emotions in two ways: (1) Cognitive Reappraisal and (2) Expressive Suppression. The cognitive reappraisal facet is a way of managing and controlling attention and cognitively changing the meaning of emotionally stimulating stimuli. It is considered a healthy emotion regulation strategy [47]. The expressive suppression involves inhibition of emotionally expressive 
behavior, thereby changing the emotional impact of a situation [48]. It is considered a less healthy emotion regulation strategy [48]. A 10-item scale ranging from 1 (strongly disagree) to 7 (strongly agree). Items $1,3,5,7$, 8, 10 make up the Cognitive Reappraisal facet and items 2, 4, 6, 9 make up the Expressive Suppression facet. Each facet's scoring is kept separate. The higher the scores, the greater the use of the emotion regulation strategy [49]. In this study, the Cronbach's alpha values for the Cognitive Reappraisal facet and for the Expressive Suppression facet were 0.764 and 0.658 respectively.

\section{Emotional eating scale (EES)}

The EES scale is composed of twenty-five items, with three derived subscales: anger, anxiety and depression. Participants rate the extent to which certain feelings lead to the urge to eat, using a five-point Likert scale ranging from 0 (no desire to eat) to 4 (an overwhelming urge to eat). Higher scores indicate a reliance on using food to help manage emotions [50]. The original EES scale had a good test-retest reliability $(\mathrm{r}=0.79, p<0.001)$ and an acceptable internal consistency Cronbach alpha $=0.81$ [51]. In this study, the Cronbach's alpha was 0.957.

\section{State adult attachment measure (SAAM)}

The SAAM measures 3 different aspects of adult attachment: security, anxiety, and avoidance. A secure attachment style is characterized by the confidence in the emotional balance in times of distress and need [52]. The attachment anxiety is characterized by a perceived failure to handle threats, which intensifies need for interpersonal closeness, love, and support [53]. The attachment avoidance is characterized by discomfort with interpersonal intimacy, hesitancy to trust others, and preventing the emotions evoked by rejection by others [54]. It consists of 21 Likert style questions ranging from 1 (strongly disagree) and 7 (strongly agree). Higher scores indicate high features of attachment [55]. In this study, the Cronbach's alpha was 0.827 .

\section{Dutch restrained eating scale}

The Dutch Restrained Eating Scale, recently validated in Lebanon [35], is a ten-item scale that assesses the frequency of dieting behaviors by using a five-point Likert scale, ranging from 1 (never) to 5 (always). The score for this scale was obtained by dividing the total items score by the total number of items. A higher score would indicate a higher degree of restrained eating. In this study, the Cronbach's alpha was 0.928 . The Arabic version can be found at the end of this manuscript (Additional file 1: Appendix 4).

\section{Translation procedure}

The forward and backward translation method was conducted in all the scales except for the HAMD, HAMA and Dutch restrained eating scales (the Arabic versions of these scales can be found in Additional file 1: Appendices 2, 3 and 4). The forward translation was done by a single bilingual translator, a health professional familiar with the terminology of the scales, whose native language is Arabic and is fluent in English. An expert committee formed by healthcare professionals and a language professional verified the Arabic translated version. A backward translation was then performed by a native English speaker translator, fluent in Arabic, and unfamiliar with the concepts of the scales. All translators were informed of the purpose of the study prior to translation. The back-translated English questionnaire was subsequently compared to the original English one, by the expert committee, aiming to discern discrepancies and to solve any inconsistencies between the two versions. Revisions of problematic questions were communicated with the translators involved for version updating. The process of forward-back translation was repeated until all ambiguities disappeared.

\section{Statistical analysis}

The SPSS software version 23 was used to conduct data analysis. Descriptive analyses were done using counts and percentages for categorical variables, mean, standard deviation for continuous measures. As for the reduction of data, an exploratory factor analysis was first executed to detect groups of factors that are reported together and are associated with $\mathrm{BE}$ in the sample. After confirming sample adequacy with the Kaiser-Meyer-Olkin (KMO) index and Bartlett's Chi-square test of sphericity, factors (groups of items) were extracted using a principal component analysis method and a promax rotation since factors were correlated. We retained factors with an Eigenvalue higher than one; we confirmed their adequacy with a Scree plot, taking into account interpretability of the results. Items with factor loading $>0.4$ were considered as loading on a factor. We also checked the reliability using Cronbach's alpha values for different factors and the total scale.

Second, a confirmatory factor analysis was carried out in Sample 2 using the maximum likelihood method for discrepancy function to assess the structure of the instrument. We also reported several goodness-of-fit indicators: the Relative Chi-square $\left(\mathrm{x}^{2} / \mathrm{df}\right)$, the Root Mean Square Error of Approximation (RMSEA), the Goodness of Fit Index (GFI) and the Adjusted Goodness of Fit Index (AGFI). The value of $x^{2}$ divided by the degrees of freedom $\left(x^{2} / d f\right)$ has a low sensitivity to sample size and may be used as an index of goodness of fit (cut-off values: $<2-5$ ). The RMSEA tests the fit of the model to the covariance matrix. As a guideline, values of $<0.05$ indicate a close fit and values below 0.11 an acceptable fit. The GFI and AGFI are Chi-square-based calculations 
independent of degrees of freedom. The recommended thresholds for acceptable values are $\geq 0.90$ [56].

The Student T-test was used to compare continuous variables in two groups. Pearson correlation was used for linear correlation between continuous variables. For categorical variables, the Chi-square and Fisher exact tests were used. The ANOVA F tests were used when comparison involved three or more groups. A post-hoc analysis, Bonferroni test was used to compare the mean difference between groups. Three hierarchical stepwise linear regressions were conducted, taking the BES as the dependent variable. All variables that showed a $p<0.1$ in the bivariate analysis were considered as important variables to be entered in the model in order to eliminate potentially confounding factors as much as possible. These three models were built by adding variables to the previous model at each step in order to determine that the newly added variables would improve the proportion of explained variance of the dependent variable by the model (improve in adjusted $\mathrm{R}^{2}$ ). In the first model the sociodemographic were considered as predictor factors, in the second model the eating behaviors were added, and in the third models the emotion scales were added. The stepwise method was used to simultaneously remove variables that were weakly correlated to the dependent variable. Thus, the final variables kept in the model better explain the distribution. A $P$-value of less than 0.05 was considered significant.

\section{Results}

\section{Study 1}

\section{Exploratory factor analysis}

None of the BES items were removed. All items could be extracted from the list since no items over-correlated to each other $(r>0.9)$, had a low loading on factors $(<$ $0.3)$ or because of a low communality $(<0.3)$. The factor analysis for the BES was run over the first sample (Total $n=406$ ). The BES items converged over a solution of two factors that had an Eigenvalue over 1, explaining a total of $41.40 \%$ of the variance. A Kaiser-Meyer-Olkin measure of sampling adequacy of 0.925 was found, with a significant Bartlett's test of sphericity $(p<0.001)$. According to the promax rotated matrix, the first factor accounted for $34.59 \%$ of the variance and the second factor accounted for $6.81 \%$. Table 2 displays the items and factor loadings for the factors. The first factor, which seems to index behavioral manifestations of BED, had strong loadings on 12 items. The second factor, which seemed to index feelings/cognitions, had high loadings on the remaining four items. Moreover, a Cronbach's alpha of 0.862 was found for the full scale, 0.826 for Factor 1 and 0.682 for Factor 2.
Table 2 Promax rotated matrix of the Arabic version of the Binge Eating Scale

\begin{tabular}{|c|c|c|}
\hline \multirow[t]{2}{*}{ BES Items } & \multicolumn{2}{|c|}{ Factor loadings } \\
\hline & Factor 1 & Factor 2 \\
\hline BES 4 & 0.750 & \\
\hline BES 15 & 0.677 & \\
\hline BES 10 & 0.619 & \\
\hline BES 9 & 0.588 & \\
\hline BES 13 & 0.586 & \\
\hline BES 5 & 0.581 & \\
\hline BES 11 & 0.553 & \\
\hline BES 7 & 0.552 & \\
\hline BES 16 & 0.544 & \\
\hline BES 2 & 0.516 & \\
\hline BES 8 & 0.508 & \\
\hline BES 3 & 0.433 & \\
\hline BES 1 & & 0.877 \\
\hline BES 6 & & 0.775 \\
\hline BES 14 & & 0.664 \\
\hline BES 12 & & 0.475 \\
\hline Cronbach alpha & 0.826 & 0.682 \\
\hline Percentage of variance explained & $34.59 \%$ & $6.81 \%$ \\
\hline
\end{tabular}

Cronbach alpha of the whole scale $=0.862$

Factor 1: Behavioral manifestations; Factor 2: Feelings/Cognitions

\section{Correlation factors}

Table 3 displays the correlation factors between each item of the BES and the whole scale. The correlation factors ranged between 0.459 and 0.660 for an individual item. To note that all factors were highly significantly correlated with the whole scale with $p<0.001$ for all of them.

\section{Study 2}

\section{Confirmatory factor analysis}

A confirmatory factor analysis was run on sample $2(n=$ 405), using the two-factor structure obtained in Sample 1. The following results were obtained: the Maximum Likelihood Chi-Square $=257$ and Degrees of Freedom $=104$, which gave a $X^{2} / d f=2.4$. For non-centrality fit indices, the Steiger-Lind RMSEA was 0.12 [0.104-0.155]. Moreover, the Joreskog GFI equaled 0.799 and AGFI equaled 0.706 .

\section{Bivariate analysis conducted on the whole sample}

A significantly higher mean of BES was found in participants with primary education compared to university education (13.04 vs. $8.65, p=0.022$ ). A significantly higher mean of BES was found in patients following a diet (10.75 vs. $8.23, p<0.001)$, patients who exercised to lose weight (10.26 vs. $8.20, p<0.001)$, patients who vomited or took laxatives to lose weight (13.37 vs. $8.51, p<0.001)$, taking 
Table 3 Correlation for each item and the total score of the Binge eating scale (BES)

\begin{tabular}{|c|c|c|}
\hline Item & Pearson Correlation coefficient ${ }^{a}$ & $p$-value \\
\hline BES 4 & 0.620 & $<0.001$ \\
\hline BES 15 & 0.579 & $<0.001$ \\
\hline BES 10 & 0.660 & $<0.001$ \\
\hline BES 9 & 0.559 & $<0.001$ \\
\hline BES 13 & 0.570 & $<0.001$ \\
\hline BES 5 & 0.526 & $<0.001$ \\
\hline BES 11 & 0.648 & $<0.001$ \\
\hline BES 7 & 0.616 & $<0.001$ \\
\hline BES 16 & 0.575 & $<0.001$ \\
\hline BES 2 & 0.584 & $<0.001$ \\
\hline BES 8 & 0.548 & $<0.001$ \\
\hline BES 3 & 0.602 & $<0.001$ \\
\hline BES 1 & 0.562 & $<0.001$ \\
\hline BES 6 & 0.583 & $<0.001$ \\
\hline BES 14 & 0.629 & $<0.001$ \\
\hline BES 12 & 0.584 & $<0.001$ \\
\hline
\end{tabular}

${ }^{\mathrm{a} C o r r e c t e d ~ i t e m-t o t a l ~ c o r r e l a t i o n s ~ w e r e ~ r e p o r t e d ~}$

diet pills (13.00 vs. $8.57, \mathrm{p}<0.001)$, starving self to lose weight $(12.20$ vs. $8.19, \mathrm{p}<0.001)$, weighing daily $(10.75$ vs. $8.58, p=0.005)$ compared to those who don't follow these eating habits. Also, a significantly higher mean of BES was found in participants that have been insulted (12.40 vs. $8.53, p<0.001)$, experienced physical abuse ( 11.26 vs. 8.80 , $p=0.014)$ and sexual abuse (15.37 vs. 8.74, $p=0.003)$, felt pressure from media to lose weight $(12.80$ vs. $8.18, p<$ $0.001)$, and have a family history of eating disorders (11.86 vs. 8.17, $\mathrm{p}<0.001)$ compared to those who do not agree with these statements.

In addition, more BE was significantly associated with more body dissatisfaction $(\mathrm{r}=0.245, \mathrm{p}<0.001)$, more restrained eating $(r=0.096, p=0.008)$, higher BMI $(r=$ $0.200, \mathrm{p}<0.001$ ), higher perceived stress (PSC score) $(\mathrm{r}=0.194, \mathrm{p}<0.001)$, higher anxiety (HAMA) $(\mathrm{r}=0.344$, $\mathrm{p}<0.001)$, higher depression (HAMD) $(\mathrm{r}=0.399, \mathrm{p}<$ 0.001 ), higher state adult attachment scale-avoidance $(\mathrm{r}=0.083, p=0.021)$, and higher emotional eating (EES scale) $(r=0.259, p<0.001)$. However, higher emotional regulation cognitive reappraisal facet, expressive suppression facet $(\mathrm{r}=-0.113, \mathrm{p}=0.003$ and $\mathrm{r}=-0.095, p=$ 0.013 respectively), and a more secure adult attachment $(\mathrm{r}=-0.173, \mathrm{p}<0.001)$ were significantly associated with less BE (Table 4). No significant association was found between BES and gender $(p=0.758)$.

\section{Multivariable analysis conducted on the whole sample} The results of a first linear regression, considering the BES to be the dependent variable and the sociodemographic as independent variables, showed that a primary level of education compared to illiteracy (Beta $=4.203$ ) was associated with more BE.

A second linear regression, taking the BES as the dependent variable and the opinion about eating habits as independent variables, showed that a higher BMI $($ Beta $=0.252)$, starving self to lose weight $($ Beta $=1.618)$, pressure from media to lose weight (Beta $=3.036)$, sexual abuse (Beta $=4.991$ ), receiving comments from the family concerning losing weight (Beta $=1.162)$ and family history of eating disorders (Beta $=1.582$ ) were associated with more BE.

A third linear regression, taking the BES as dependent variable and the scales and opinion about eating habits as independent variables, showed that higher BMI $($ Beta $=0.185)$, higher depression $($ Beta $=0.298)$, higher anxiety $($ Beta $=0.070)$, higher emotional eating (Beta $=$ 0.072 ), greater body dissatisfaction (Beta $=0.198$ ) and greater pressure from media to lose weight (Beta = 2.010), were associated with higher BE. Higher expressive suppression facet (Beta $=-0.108)$ was associated with lower BE (Table 5).

\section{Discussion}

Although there are numerous studies on BE behavior worldwide, studies on this behavior in Lebanon remain limited. Therefore, this cross-sectional study aimed to evaluate the psychometric properties of an Arabic version of the BES and to determine the correlates of BED among a sample of the Lebanese population. The results demonstrated that the Arabic version of this tool had a very good internal consistency and a good construct validity. Our results also showed that higher BMI, starving self to lose weight, feeling pressure from media to lose weight, a history of sexual abuse, a family history of eating disorders, higher depression and anxiety scores, higher emotional eating, and greater body dissatisfaction were associated with higher $\mathrm{BE}$ scores. A low monthly income compared to no income and a higher expressive suppression facet score were associated with lower BE scores.

\section{Validation of the BES}

The factor structure of the Arabic version revealed two main factors, in line with the Malay study [31]. Also, another study done among a sample of bariatric surgery candidates on the replication and evaluation of BES found that a two-factor model improved significantly the model fit, supporting the presence of a higher-order severity factor accounting for a significant amount of variance [57]. The internal consistency of our results was similar to the original scale [25] and to the other versions (Cronbach alpha ranged from 0.85 [30] to 0.93 [27]). 
Table 4 Bivariate analysis of the factors associated with the Binge Eating Scale (BES) score

\begin{tabular}{lll}
\hline BES & $p$-value \\
& Mean \pm SD & \\
\hline
\end{tabular}

Education level $^{+}$

Primary

$13.04 \pm 9.36$

0.022

Complementary

$8.65 \pm 6.86$

Secondary

$9.95 \pm 8.25$

University

$8.65 \pm 7.43$

Monthly income

Low

Intermediate

High

Dieted to lose

weight (past 30 days)

Yes

No

$10.75 \pm 7.74$

$8.23 \pm 7.47$

Exercised to lose

weight (past 30 days)

Yes

No

Vomited or taken laxatives

to lose weight (past 30 days)

$$
\text { Yes }
$$

No

$8.69 \pm 7.44$

$9.64 \pm 8.84$

$9.26 \pm 7.75$

$10.26 \pm 7.72$

$8.20 \pm 7.47$

$13.37 \pm 7.29$

$8.51 \pm 7.53$

Taken diet pills to lose

weight (past 30 days)

Yes

No

$13.00 \pm 7.69$

$8.57 \pm 7.53$

Starving self to lose

weight (past 30 days)

Yes

No

$12.20 \pm 8.20$

$8.19 \pm 7.30$

Daily weighing

Yes

No

Receiving comments from the family concerning losing weight

$\begin{array}{ll}\text { Yes } & 10.90 \pm 8.03 \\ \text { No } & 8.12 \pm 7.32\end{array}$

Have you been

insulted

Yes

No

$12.40 \pm 8.46$

$8.53 \pm 7.34$

Have you been physically abused

$$
\text { Yes }
$$

No

$11.26 \pm 8.68$

$8.80 \pm 7.53$

Have you been

$<0.001$

0.005
Table 4 Bivariate analysis of the factors associated with the

\begin{tabular}{|c|c|c|}
\hline & BES & \multirow[t]{2}{*}{$p$-value } \\
\hline & Mean \pm SD & \\
\hline \multicolumn{3}{|c|}{ sexually abused } \\
\hline Yes & $15.37 \pm 10.26$ & \multirow[t]{2}{*}{0.003} \\
\hline No & $8.74 \pm 7.44$ & \\
\hline \multicolumn{3}{|c|}{$\begin{array}{l}\text { Have you been in } \\
\text { a bad romantic } \\
\text { relationship }\end{array}$} \\
\hline Yes & $10.44 \pm 8.10$ & \multirow[t]{2}{*}{0.001} \\
\hline No & $8.38 \pm 7.38$ & \\
\hline \multicolumn{3}{|c|}{$\begin{array}{l}\text { Family history of } \\
\text { eating disorders }\end{array}$} \\
\hline Yes & $11.86 \pm 8.08$ & \multirow[t]{2}{*}{$<0.001$} \\
\hline No & $8.17 \pm 7.33$ & \\
\hline
\end{tabular}
Binge Eating Scale (BES) score (Continued)

Pressure from TV,

magazine to lose

your weight

Yes

$12.80 \pm 8.07$

$<0.001$

No

$8.18 \pm 7.31$

Pearson correlation p-value coefficient

Body dissatisfaction score

0.245

$<0.00$

Restrained eating scale

0.096

0.008

Body Mass Index

0.200

$<0.001$

Perceived stress scale

0.194

$<0.001$

Anxiety

0.344

$<0.001$

Depression

0.399

$<0.001$

ERQ cognitive

reappraisal facet

ERQ expressive

suppression facet

State Adult attachment

scale-security

State Adult attachment

scale-avoidance

$-0.113$

0.003

$-0.095$

0.013

$-0.173$

$<0.001$

EES scale

0.083

0.021

ERQ Emotional Regulation Questionnaire, EES Emotional Eating Scale ${ }^{+}$One-way analysis of variance (ANOVA): post hoc analysis for education level: primary vs. complementary (13.04 vs. $8.65, p=0.111)$; primary vs. secondary (13.04 vs. $9.95, p=0.449)$; primary vs. university $(13.04$ vs. $8.65, p=0.04)$; complementary vs. secondary ( 8.65 vs. $9.95, p=1.000)$; complementary vs. university ( 8.65 vs. $8.65, p=1.000)$; secondary vs. university (9.95 vs. $8.65, p=0.536)$

All BES items positively correlated above 0.5 , indicating good predictive value. This was similar to a study done by Grupski et al. that found nearly half of the items correlated positively [58], but conflicted with the study done by Greeno et al., which found very low correlations for most items [44]. The inconsistency in results between the studies might be due to methodological differences and/or sample characteristics. The results obtained in Sample 1 
Table 5 Multivariable analysis

\begin{tabular}{llll} 
Unstandardized & $\begin{array}{l}\text { Standardized } \\
\text { Beta }\end{array}$ & $p$-value & Confidence interval \\
\cline { 3 - 4 } & Lower Bound Upper Bound
\end{tabular}

Model 1: Linear regression taking the Binge Eating Scale (BES) as dependent variable and the sociodemographic characteristics as independent variables.

Primary vs illiterate* level of education

Variables entered: Education level.

Model 2: Linear regression taking the Binge Eating Scale (BES) as dependent variable and the opinion about eating habits as independent variables.

Pressure from TV, magazine to lose your weight (yes vs no*)

Body Mass Index (BMI)

History of sexual abuse (yes vs no*)

Receiving comments from the family concerning losing weight

Variables entered $=\mathrm{BMI}$, education level, Exercised to lose weight (past 30 days), Dieted to lose weight (past 30 days), Vomited or taken laxatives to lose weight (past 30 days), Taken diet pills to lose weight (past 30 days), Starving self to lose weight (past 30 days), Daily weighing, Receiving comments from the family concerning losing weight, Have you been insulted, Have you been physically abused, Have you been Sexually abused, Have you been in a bad romantic relationship, family history of eating disorders, Pressure from TV, magazine to lose your weight.

Model 3: Linear regression taking the Binge Eating Scale (BES) as dependent variable and the eating disorders and emotion scales and opinion about eating habits as independent variables.

Depression

Body dissatisfaction

Emotional eating

Body Mass Index (BMI)

Pressure from TV, magazine to lose your weight (yes vs no*)

Anxiety

Emotional regulation expressive suppression facet

Variables entered in the model: BMI, education level, Exercised to lose weight (past 30 days), Dieted to lose weight (past 30 days), Vomited or taken laxatives to lose weight (past 30 days), Taken diet pills to lose weight (past 30 days), Starving self to lose weight (past 30 days), Daily weighing, Receiving comments from the family concerning losing weight, Have you been insulted, Have you been physically abused, Have you been Sexually abused, Have you been in a bad romantic relationship, family history of eating disorders, Pressure from TV, magazine to lose your weight, Body dissatisfaction score, Restrained eating scale, Perceived stress scale, HAMA, HAMD, ERQ cognitive reappraisal facet, ERQ expressive suppression facet, State Adult attachment scale and EES scale

\section{*Reference group}

were confirmed later on a second sample, which further solidify the validation of the scale in its Arabic form. The findings of this study demonstrate that the Arabic version of the BES is a valid scale for the assessment of BED the Lebanese general population. This easy-to-administer 16item scale can be used to provide relevant information about the symptoms and the severity of the BED.

\section{Binge eating correlates}

The results of our study showed that increased depression scores were associated with higher scores on the BES. In fact, comorbid depression has been found in $30-50 \%$ of patients suffering from $\mathrm{BE}[59,60]$. The association between these two disorders has been the subject of many studies and predicts symptoms of $\mathrm{BE}$ in white 
women [61], middle school students [62] and adolescent girls [63]. In a recent meta-analysis, previous authors $[55,64]$ have shown a reciprocal relationship between depression and BED; in fact depression can be a risk factor for BED, or a result of it. This dual relationship would emphasize the presence of common predisposing factors between the two disorders. Another possible explanation presented in previous studies is that exposure to a food with a pleasant taste is able to cause the activation of brain regions involved in feelings of reward in patients with a high level of negative emotions (such as depression) [65].

Moreover, the multivariable analysis indicates that higher anxiety was associated with more pronounced $\mathrm{BE}$, in line with previous studies [66-69]. The comorbidity rate between BED and anxiety disorders is high, with a lifetime prevalence of $37 \%$ among patients suffering from BED [70]. In fact, anxiety disorders are the second most common comorbidity in BED subjects [70]. On the one hand, some studies suggest that anxiety may be secondary to overeating [71]; some genetic data has shown that people with BED have an increased risk of anxiety symptoms, regardless of BMI [72]. On the other hand, retrospective studies have shown that anxiety has been identified as a risk factor for various eating disorders, including BED [73, 74]; more specifically, anxiety disorders generally precede eating disorders, with early onset during childhood $[75,76]$. Whether anxiety is a risk factor for BED or a consequence, the literature suggests that $\mathrm{BE}$ and anxiety can be linked through common vulnerability factors such as distal stress (for example, during childhood), proximal stress, and childhood stressors (teasing and bullying) [76].

More body dissatisfaction was also associated with greater $\mathrm{BE}$, according to our results. In addition to the risk factors, the triggering and sustaining factors of the BED have been identified and integrated into a recent Tuschen-Caffier and Hilbert model [77]. Based on this model, the authors pointed out that there are different external and internal stressors (relationship conflicts, exposure to food, impulsivity, low self-esteem, tensions) that can trigger $\mathrm{BE}$. In addition, they add that over concentration on weight and shape, as well as body dissatisfaction, are risk factors for the etiology, maintenance and relapse of BED. This model is in line with other studies $[78,79]$. Other studies have shown that subjects with BED exhibited negative emotions and had more negative body-related cognitions when examining their own bodies than healthy controls $[80,81]$. This disturbed perception of body size and shape may be related to a biased treatment of information, which is now considered an important factor in the development and maintenance of body image disruption in the pathology of the BED $[82,83]$. Therefore, this erroneous treatment of information will be an important aspect of psychotherapeutic work in BED subjects $[84,85]$.

In our study, higher expressive suppression facet was associated with lower BE. Strategies for regulating inappropriate negative emotions (such as disappointment, suffering, loneliness, etc.) have been shown to play a role in the appearance and maintenance of $\operatorname{BED}[86,87]$. More particularly, people with BED tend to suppress and ruminate on their undesirable emotions, resulting in an increase in psychopathological beliefs and symptoms $[88,89]$. Emotional eating was found to be positively related to BE. In fact, overeating just for emotional reasons and cravings may turn quickly into BED [90].

According to our results, a positive and significant correlation was found between a history of sexual abuse and BED, in line with several studies [91, 92]. A correlation was found between traumatic events and eating disorders used as a means of self-management of feelings and experiences related to trauma. Specifically, previous findings $[91,93]$ have found that $30 \%$ of children with an eating disorder have been sexually abused, with BED, in particular, being linked to trauma as a means of self-protection. The cycle of frenzy/overeating behaviors seems to reduce awareness of thoughts and emotions as a way of evading negative emotions that accompany traumatic experiences [94].

As for BMI, our results showed that a higher BMI was associated with higher BED. Previous findings [95] have focused on the significant correlation between obesity and BED and hypothesize that these conditions may potentially contribute to one another and/or exacerbate each other. The co-existence between obesity and BED is of concern due to the medical and psychosocial risks [96].

As for pressure from media, our results indicated a positive correlation between $\mathrm{BE}$ and pressure from media to lose weight. Few studies exist specifically on BED and media, but different studies have shown a direct relationship between media exposure, media pressure, eating disorders, body dissatisfaction, and negative affect [97].

Finally, results of our study indicate that a family history of eating disorders was associated with higher $\mathrm{BE}$. BED was found to aggregate strongly within families, which may reflect genetic influences [98, 99]. Also, a population-based twin study found a considerable heritability estimate $(41 \%)$ for the BED, thus supporting the heritable nature of this syndrome [72]. Although family and twin studies have suggested the role of genetics in $\mathrm{BED}$, gene studies have not confirmed the involvement of a particular gene or genetic pathway. Both genetic and environmental factors are now hypothesized to work together in order to influence the risk for eating disorders. Studies have not yet reached a definitive measure of the extent of relative importance of each component 
due to the difficulty in statistically distinguishing between the genetic and environmental factors involved in the association [100].

\section{Limitations}

There are many limitations in this study. First, we relied on participants to provide us with information on $\mathrm{BE}$, depression, anxiety, emotion regulation, body dissatisfaction and others using self-report questionnaires. Second, the study has a cross sectional design and causality cannot be proved. Third, although the sample was randomly selected across Lebanese regions, the majority was young, single, with a university degree, which hinders the generalizability of the results. Fourth, test-retest reliability was not assessed. Finally, many scales used were not validated in Lebanon. Nonetheless the authors believe that their findings are noteworthy, since they are consistent with other recent studies.

\section{Conclusion}

The results showed that the Arabic version of the BES could be used as an appropriate measure for assessing $\mathrm{BE}$ behaviors in clinical practice and research. The findings suggest that the scale is bi-factorial. The study also found that having higher BES scores is associated with being dissatisfied with one's body size, having a history of sexual abuse, a family history of BE, increased depressive/anxiety symptoms, and lower self-esteem.

Comprehensive treatments should address the psychological antecedents and consequences of this behavior, as they are critically important to the syndromal nature of BED. It is in this context that the role of mental health professionals is essential in providing interventions for long-term $\mathrm{BE}$ episodes and dealing with negative emotions and related psychological factors. Moreover, this study suggests putting into action certain behaviors aimed at preventing individuals from engaging in excessive food consumption: 1) an increase and improvement in family and relational interactions, 2) the promotion of a positive body image, and better self-esteem by professionals and in media 3) prevention of depression and anxiety. These recommendations must be incorporated into intervention programs on eating behavior. Psychologists, counselors, and nutritionists should also work together to improve people's eating habits, nutritional status, and mental health.

\section{Supplementary information}

Supplementary information accompanies this paper at https://doi.org/10. 1186/s40337-019-0270-2.

Additional file 1: Appendix 1. The Arabic version of the Binge Eating Scale. Appendix 2. The Arabic version of the Hamilton Anxiety Rating
Scale (HAM-A). Appendix 3. The Arabic version of the Hamilton Scale for Depression (HAM-D). Appendix 4. The Arabic version of the Dutch Restrained Eating Scale.

\section{Abbreviations}

AGFI: Adjusted Goodness of Fit Index; ANOVA: Analysis of variance; BE: Binge eating; BED: Binge eating disorder; BES: Binge Eating Scale; BMI: Body Mass Index; DSM-5: Diagnostic and Statistical Manual of Mental Disorders, Fifth Edition; DSM-IV: Fourth Edition of the Diagnostic and Statistical Manual of Mental Disorders; ED: Eating disorder; EDI-2: Body dissatisfaction subscale of the Eating Disorder Inventory-second version; EDNOS: Eating disorder not otherwise specified; EES: Emotional eating scale; ERQ: Emotion Regulation Questionnaire; GFI: Goodness of Fit Index; HAM-A: Hamilton Anxiety Rating Scale; HAM-D: Hamilton Scale for Depression; KMO: Kaiser-Meyer-Olkin; PSS: Perceived Stress Scale; RMSEA: Root Mean Square Error of Approximation; SAAM: State adult attachment measure

\section{Acknowledgments}

Cloe Zeidan for proofreading the article. All participants who helped us filling the questionnaire.

\section{Authors' contributions}

$\mathrm{SO}$ and $\mathrm{SH}$ conceived and designed the survey. MA, KH, MA and NK performed the data collection and entry. $\mathrm{CH}$ and $\mathrm{SH}$ were involved in the statistical analysis and data interpretation. RZ and CH wrote the manuscript. All authors read the manuscript, critically revised it for intellectual content, and approved the final version.

\section{Funding}

None.

\section{Availability of data and materials}

The authors do not have the right to share any data information as per their institutions policies.

\section{Ethics approval and consent to participate}

The Psychiatric Hospital of the Cross Ethics and Research Committee, in compliance with the Hospital's Regulatory Research Protocol, approved this study protocol (HPC-020-2018) based on the fact that the autonomy and confidentiality of participants were respected and since it was an observational study, no harm will be prompted to them. The purpose and requirement of the study were informed to each participant. A signed informed consent was obtained from each participant.

\section{Consent for publication}

All authors gave their consent for publication.

\section{Competing interests}

The authors declare that they have no competing interests.

\section{Author details}

${ }^{1}$ Faculty of Public Health, Lebanese University, Fanar, Lebanon. ${ }^{2}$ INSPECT-LB: Institut National de Santé Publique, Epidemiologie Clinique et Toxicologie, Beirut, Lebanon. ${ }^{3} \mathrm{CERIPH}$ : Center for Research in Public Health,

Pharmacoepidemiology Surveillance Unit, Faculty of Public Health, Lebanese University, Fanar, Lebanon. ${ }^{4}$ Psychiatric Hospital of the Cross, P.O. Box 60096, Jall-Eddib, Lebanon. ${ }^{5}$ Univ. Limoges, UMR 1094, Neuroépidémiologie Tropicale, Institut d'Epidémiologie et de Neurologie Tropicale, GEIST, 87000 Limoges, France. ${ }^{6}$ Faculty of Medicine and Medical Sciences, Holy Spirit University of Kaslik (USEK), Jounieh, Lebanon. ${ }^{7}$ School of Pharmacy, Lebanese International University, Beirut, Lebanon. ${ }^{8}$ Faculty of Pedagogy, Holy Family University, Batroun 5534, Lebanon. ${ }^{9}$ Faculty of Arts and Sciences, Holy Spirit University (USEK), Jounieh, Lebanon.

Received: 10 May 2019 Accepted: 23 October 2019

Published online: 01 December 2019

\section{References}

1. Dingemans $A E$, Bruna MJ, van Furth EF. Binge eating disorder: a review. Int J Obes Relat Metab Disord. 2002;26:299-307. 
2. American Psychiatric Association, editor. Diagnostic and statistical manual of mental disorders. 5th ed: American Psychiatric Association; 2013. Available from: https://psychiatryonline.org/doi/book/10.1176/appi.books.9780890425596

3. Kessler RC, Berglund PA, Chiu WT, Deitz AC, Hudson Jl, Shahly V, et al. The prevalence and correlates of binge eating disorder in the World Health Organization world mental health surveys. Biol Psychiatry. 2013; 73:904-14.

4. Myers LL, Wiman AM. Binge eating disorder: a review of a new DSM diagnosis. Res Soc Work Pract. 2014;24:86-95.

5. Hoek HW. Epidemiology of eating disorders in persons other than the high-risk group of young Western females. Curr Opin Psychiatry. 2014; 27:423-5.

6. Smink FR, van Hoeken D, Hoek HW. Epidemiology of eating disorders: incidence, prevalence and mortality rates. Curr Psychiatry Rep. 2012;14:406-14.

7. Pike KM, Hoek HW, Dunne PE. Cultural trends and eating disorders. Curr Opin Psychiatry. 2014;27:436-42.

8. Erskine HE, Whiteford HA, Pike KM. The global burden of eating disorders. Curr Opin Psychiatry. 2016;29:346-53.

9. Popkin BM, Adair LS, Ng SW. Global nutrition transition and the pandemic of obesity in developing countries. Nutr Rev. 2012;70:3-21.

10. Agh T, Kovacs G, Pawaskar M, Supina D, Inotai A, Voko Z. Epidemiology, health-related quality of life and economic burden of binge eating disorder: a systematic literature review. Eat Weight Disord. 2015;20:1-12.

11. Fairburn CG, Doll HA, Welch SL, Hay PJ, Davies BA, O'Connor ME. Risk factors for binge eating disorder: a community-based, case-control study. Arch Gen Psychiatry. 1998;55:425-32.

12. Gearhardt AN, White MA, Potenza MN. Binge eating disorder and food addiction. Curr Drug Abuse Rev. 2011;4:201-7.

13. Schulte EM, Grilo CM, Gearhardt AN. Shared and unique mechanisms underlying binge eating disorder and addictive disorders. Clin Psychol Rev. 2016:44:125-39.

14. Allison KC, Grilo CM, Masheb RM, Stunkard AJ. High self-reported rates of neglect and emotional abuse, by persons with binge eating disorder and night eating syndrome. Behav Res Ther. 2007;45:2874-83.

15. Harrington EF, Crowther $\mathrm{JH}$, Henrickson HC, Mickelson KD. The relationships among trauma, stress, ethnicity, and binge eating. Cultur Divers Ethnic Minor Psychol. 2006;12:212-29.

16. Naish KR, Laliberte M, MacKillop J, Balodis IM. Systematic review of the effects of acute stress in binge eating disorder. Eur J Neurosci. 2018.

17. Nasser M. Comparative study of the prevalence of abnormal eating attitudes among Arab female students of both London and Cairo universities. Psychol Med. 1986;16:621-5.

18. Nasser M. The psychometric properties of the eating attitude test in a nonWestern population. Soc Psychiatry Psychiatr Epidemiol. 1994;29:88-94.

19. Dolan B, Ford K. Binge eating and dietary restraint: a cross-cultural analysis. Int J Eat Disord. 1991;10:345-53.

20. Mousa TY, Al-Domi HA, Mashal RH, Jibril MA-K. Eating disturbances among adolescent schoolgirls in Jordan. Appetite. 2010;54:196-201.

21. Rabie MA, Abo-El-Ezz NF, El-din M. Anxiety and social anxiety symptoms among overweight females seeking treatment for obesity. Curr Psychiatr Ther. 2010;17:13-20.

22. Schulte SJ. Predictors of binge eating in male and female youths in the United Arab Emirates. Appetite. 2016;105:312-9.

23. Doumit R, Khazen G, Katsounari I, Kazandjian C, Long J, Zeeni N. Investigating vulnerability for developing eating disorders in a multiconfessional population. Community Ment Health J. 2017;53:107-16.

24. Zeeni N, Safieddine H, Doumit R. Eating disorders in Lebanon: directions for public health action. Community Ment Health J. 2017;53:117-25.

25. Gormally J, Black S, Daston S, Rardin D. The assessment of binge eating severity among obese persons. Addict Behav. 1982;7:47-55.

26. Hood MM, Grupski AE, Hall BJ, Ivan I, Corsica J. Factor structure and predictive utility of the binge eating scale in bariatric surgery candidates. Surg Obes Relat Dis. 2013;9:942-8.

27. Brunault P, Gaillard P, Ballon N, Couet C, Isnard P, Cook S, et al. Validation of the French version of the binge eating scale: examination of its factor structure, internal consistency and construct validity in a non-clinical and a clinical population. Encephale. 2016;42:426-33.

28. Imperatori C, Innamorati M, Lamis DA, Contardi A, Continisio M, Castelnuovo $\mathrm{G}$, et al. Factor structure of the binge eating scale in a large sample of obese and overweight patients attending low energy diet therapy. Eur Eat Disord Rev. 2016;24:174-8.
29. Partida O, Garcia R, Cardenas A, Agraz F. Evaluation of the binge eating scale in Mexican population: translation and psychometric properties of the Spanish version. Psiquiatria. 2006;22:6.

30. Mootabi F, Moloodi R, Dezhkam M, Omidvar N. Standardization of the binge eating scale among Iranian obese population. Iran J Psychiatry. 2009;4:143-6.

31. Robert SA, Rohana AG, Suehazlyn Z, Maniam T, Azhar SS, Azmi KN. The validation of the malay version of binge eating scale: a comparison with the structured clinical interview for the DSM-IV. J Eat Disord. 2013;1:28.

32. Duarte C, Pinto-Gouveia J, Ferreira C. Expanding binge eating assessment: validity and screening value of the binge eating scale in women from the general population. Eat Behav. 2015;18:41-7.

33. Zúñiga $\mathrm{O}$, Robles $\mathrm{R}$. Validez de constructo y consistencia interna de Cuestionario de Trastorno por Atracón en población mexicana con obesidad. Psiquis. 2006;15:126-34.

34. Escrivá-Martínez T, Galiana L, Rodriguez-Arias M, Baños RM. The binge eating scale: structural equation competitive models, invariance measurement between sexes, and relationships with food addiction, impulsivity, binge drinking, and body mass index. Front Psychol. 2019;10:530.

35. Saade S, Hallit S, Haddad C, Hallit R, Akel M, Honein K, et al. Factors associated with restrained eating and validation of the Arabic version of the restrained eating scale among an adult representative sample of the Lebanese population: a cross-sectional study. J Eat Disord. 2019;7:24.

36. Haddad C, Hallit R, Akel M, et al. Validation of the Arabic version of the ORTO-15 questionnaire in a sample of the Lebanese population. Eat Weight Disord. 2019. https://doi.org/10.1007/s40519-019-00710-y.

37. Haddad C, Zakhour M, Akel M, Honein K, Akiki M, Hallit S, et al. Factors associated with body dissatisfaction among the Lebanese population. Eat Weight Disord. 2019;24:507-19. https://doi.org/10.1007/s40519-018-00634-z.

38. Haddad C, Obeid S, Akel M, Honein K, Akiki M, Azar J, et al. Correlates of orthorexia nervosa among a representative sample of the Lebanese population. Eat Weight Disord. 2019;24:481-93. https://doi.org/10.1007/ s40519-018-0631-x.

39. Comrey AL, Lee HB. A first course in factor analysis: Psychology press; 2013.

40. Weary-Smith KA. Validation of the physical activity index (PAI) as a measure of total activity load and total kilocalorie expenditure during submaximal treadmill walking: University of Pittsburgh; 2007.

41. Rosenberg M. Rosenberg self-esteem scale (RSE). Acceptance and commitment therapy Measures package, vol. 61; 1965.

42. Cohen S, Kamarck T, Mermelstein R. Perceived stress scale. Measuring stress: a guide for health and social scientists, vol. 10; 1994.

43. Hallit S, Haddad C, Hallit R, Akel M, Obeid S, Haddad G, et al. Validation of the Hamilton anxiety rating scale and state trait anxiety inventory a and B in Arabic among the Lebanese population. Clin Epidemiol Glob Health. 2019;7:464-70. https://doi.org/10.1016/j.cegh.2019.02.002.

44. Greeno CG, Marcus MD, Wing RR. Diagnosis of binge eating disorder: discrepancies between a questionnaire and clinical interview. Int J Eat Disord. 1995;17:153-60.

45. Garner DM. The Eating Disorder Inventory-2. Professional manual. Odessa: Psychological Assessment Resources, Inc.; 1991.

46. Obeid S, Abi Elias Hallit C, Haddad C, Hany Z, Hallit S. Validation of the Hamilton depression rating scale (HDRS) and sociodemographic factors associated with Lebanese depressed patients. Encephale. 2018;44:397-402.

47. Gross JJ. Emotion regulation: affective, cognitive, and social consequences. Psychophysiology. 2002;39:281-91.

48. Gross JJ, Levenson RW. Emotional suppression: physiology, self-report, and expressive behavior. J Pers Soc Psychol. 1993;64:970-86.

49. Gross JJ, John OP. Individual differences in two emotion regulation processes: implications for affect, relationships, and well-being. J Pers Soc Psychol. 2003;85:348-62.

50. Beaton DE, Bombardier C, Guillemin F, Ferraz MB. Guidelines for the process of cross-cultural adaptation of self-report measures. Spine (Phila Pa 1976). 2000;25:3186-91.

51. Arnow B, Kenardy J, Agras WS. The emotional eating scale: the development of a measure to assess coping with negative affect by eating. Int J Eat Disord. 1995;18:79-90.

52. Bowlby J. A secure base: parent-child attachment and healthy human development: Basic books; 2008.

53. Griffin DW, Bartholomew K. Models of the self and other: fundamental dimensions underlying measures of adult attachment. J Pers Soc Psychol. 1994;67:430

54. Bartholomew K. Avoidance of intimacy: an attachment perspective. J Soc Pers Relat. 1990;7:147-78. 
55. Puccio F, Fuller-Tyszkiewicz M, Ong D, Krug I. A systematic review and meta-analysis on the longitudinal relationship between eating pathology and depression. Int J Eat Disord. 2016;49:439-54.

56. Marsh HW, Hau K-T, Wen Z. In search of golden rules: comment on hypothesis-testing approaches to setting cutoff values for fit indexes and dangers in overgeneralizing Hu and Bentler's (1999) findings. Struct Equ Modeling. 2004;11:320-41.

57. Marek RJ, Tarescavage AM, Ben-Porath YS, Ashton K, Heinberg LJ. Replication and evaluation of a proposed two-factor binge eating scale (BES) structure in a sample of bariatric surgery candidates. Surg Obes Relat Dis. 2015;11:659-65.

58. Grupski AE, Hood MM, Hall BJ, Azarbad L, Fitzpatrick SL, Corsica JA. Examining the binge eating scale in screening for binge eating disorder in bariatric surgery candidates. Obes Surg. 2013;23:1-6.

59. Hudson Jl, Hiripi E, Pope HG Jr, Kessler RC. The prevalence and correlates of eating disorders in the National Comorbidity Survey Replication. Biol Psychiatry. 2007:61:348-58

60. Swanson SA, Crow SJ, Le Grange D, Swendsen J, Merikangas KR. Prevalence and correlates of eating disorders in adolescents. Results from the national comorbidity survey replication adolescent supplement. Arch Gen Psychiatry. 2011;68:714-23.

61. Mitchell KS, Mazzeo SE. Binge eating and psychological distress in ethnically diverse undergraduate men and women. Eat Behav. 2004;5:157-69.

62. Pearson CM, Zapolski TC, Smith GT. A longitudinal test of impulsivity and depression pathways to early binge eating onset. Int J Eat Disord. 2015;48: 230-7.

63. Skinner $\mathrm{HH}$, Haines J, Austin SB, Field AE. A prospective study of overeating, binge eating, and depressive symptoms among adolescent and young adult women. J Adolesc Health. 2012;50:478-83.

64. Culbert KM, Racine SE, Klump KL. Research review: what we have learned about the causes of eating disorders - a synthesis of sociocultural, psychological, and biological research. J Child Psychol Psychiatry. 2015;56: 1141-64.

65. Bohon C, Stice E. Negative affect and neural response to palatable food intake in bulimia nervosa. Appetite. 2012;58:964-70.

66. Azarbad L, Corsica J, Hall B, Hood M. Psychosocial correlates of binge eating in Hispanic, African American, and Caucasian women presenting for bariatric surgery. Eat Behav. 2010;11:79-84.

67. Jones-Corneille LR, Wadden TA, Sarwer DB, Faulconbridge LF, Fabricatore AN, Stack RM, et al. Axis I psychopathology in bariatric surgery candidates with and without binge eating disorder: results of structured clinical interviews. Obes Surg. 2012;22:389-97.

68. Peterson CB, Thuras P, Ackard DM, Mitchell JE, Berg K, Sandager N, et al. Personality dimensions in bulimia nervosa, binge eating disorder, and obesity. Compr Psychiatry. 2010:51:31-6.

69. Fandiño J, Moreira RO, Preissler C, Gaya CW, Papelbaum M, Coutinho WF, et al. Impact of binge eating disorder in the psychopathological profile of obese women. Compr Psychiatry. 2010;51:110-4.

70. Grilo CM, White MA, Masheb RM. DSM-IV psychiatric disorder comorbidity and its correlates in binge eating disorder. Int J Eat Disord. 2009;42:228-34

71. Tanofsky-Kraff M, Shomaker LB, Olsen C, Roza CA, Wolkoff LE, Columbo KM, et al. A prospective study of pediatric loss of control eating and psychological outcomes. J Abnorm Psychol. 2011;120:108.

72. Reichborn-Kjennerud T, Bulik CM, Tambs K, Harris JR. Genetic and environmental influences on binge eating in the absence of compensatory behaviors: a population-based twin study. Int J Eat Disord. 2004;36:307-14.

73. Pallister $\mathrm{E}$, Waller $\mathrm{G}$. Anxiety in the eating disorders: understanding the overlap. Clin Psychol Rev. 2008;28:366-86.

74. Bulik CM, Sullivan PF, Carter FA, Joyce PR. Lifetime anxiety disorders in women with bulimia nervosa. Compr Psychiatry. 1996;37:368-74.

75. Kaye WH, Bulik CM, Thornton L, Barbarich N, Masters K, Group P.F.C. Comorbidity of anxiety disorders with anorexia and bulimia nervosa. Am J Psychiatry. 2004;161:2215-21.

76. Godart NT, Flament MF, Curt F, Perdereau F, Lang F, Venisse JL, et al. Anxiety disorders in subjects seeking treatment for eating disorders: a DSMIV controlled study. Psychiatry Res. 2003;117:245-58.

77. Tuschen-Caffier B, Hilbert A. Binge-Eating-Störung [Binge Eating Disorder]. Göttingen: Hogrefe; 2016

78. Lammers MW, Vroling MS, Ouwens MA, Engels RC, van Strien T. Predictors of outcome for cognitive behaviour therapy in binge eating disorder. Eur Eat Disord Rev. 2015;23:219-28
79. Jacobi C, Hayward C, de Zwaan M, Kraemer HC, Agras WS. Coming to terms with risk factors for eating disorders: application of risk terminology and suggestions for a general taxonomy. Psychol Bull. 2004;130:19.

80. Bauer A, Schneider S, Waldorf M, Cordes M, Huber TJ, Braks K, et al. Visual processing of one's own body over the course of time: evidence for the vigilance-avoidance theory in adolescents with anorexia nervosa? Int J Eat Disord. 2017:50:1205-13.

81. Vocks S, Legenbauer T, Wächter A, Wucherer M, Kosfelder J. What happens in the course of body exposure?: emotional, cognitive, and physiological reactions to mirror confrontation in eating disorders. J Psychosom Res. 2007;62:231-9.

82. Aspen $\mathrm{V}$, Darcy AM, Lock J. A review of attention biases in women with eating disorders. Cognit Emot. 2013;27:820-38.

83. Rodgers RF, DuBois RH. Cognitive biases to appearance-related stimuli in body dissatisfaction: a systematic review. Clin Psychol Rev. 2016:46:1-11.

84. Delinsky SS, Wilson GT. Mirror exposure for the treatment of body image disturbance. Int J Eat Disord. 2006:39:108-16.

85. Vocks S, Legenbauer T, Troje N, Schulte D. Body image therapy in eating disorders. Influencing of perceptive, cognitive-affective, and behavioral components of the body image. Zeitschrift fur klinische Psychologie und Psychotherapie-Gottingen. 2006;35:286.

86. Zerwas S, Larsen JT, Petersen L, Thornton LM, Mortensen PB, Bulik CM. The incidence of eating disorders in a Danish register study: associations with suicide risk and mortality. J Psychiatr Res. 2015;65:16-22.

87. Keski-Rahkonen A, Mustelin L. Epidemiology of eating disorders in Europe: prevalence, incidence, comorbidity, course, consequences, and risk factors. Curr Opin Psychiatry. 2016;29:340-5

88. Svaldi J, Griepenstroh J, Tuschen-Caffier B, Ehring T. Emotion regulation deficits in eating disorders: a marker of eating pathology or general psychopathology? Psychiatry Res. 2012;197:103-11.

89. Nolen-Hoeksema S, Blair E, Sonja L. Rethinking rumination. Pers Psychol Sci. 2008:3:400-24.

90. Svaldi J, Caffier D, Tuschen-Caffier B. Emotion suppression but not reappraisal increases desire to binge in women with binge eating disorder. Psychother Psychosom. 2010;79:188-90.

91. Dunkley DM, Masheb RM, Grilo CM. Childhood maltreatment, depressive symptoms, and body dissatisfaction in patients with binge eating disorder: the mediating role of self-criticism. Int J Eat Disord. 2010;43:274-81.

92. Eating Disorders and Trauma / PTSD (Post Traumatic Stress Disorder) CoOccurring Eating Disorder Hope. Eating disorder help treatment, recovery articles, facts \& Statistics on anorexia and bulimia eating disorder Hope; 2012. Available from: http://www.eatingdisorderhope.com/treatment-foreating-disorders/co-occurring-dualdiagnosis/trauma-ptsd\#Connection-andRelationship-between-Trauma-and-Eating-Disorders

93. Johnson JG, Cohen P, Kasen S, Brook JS. Childhood adversities associated with risk for eating disorders or weight problems during adolescence or early adulthood. Am J Psychiatry. 2002;159:394-400.

94. Cash TF, Smolak L. Body image: a handbook of science, practice, and prevention. New York: Guilford Press; 2011.

95. Palavras MA, Kaio GH, Mari JJ, Claudino AM. A review of Latin American studies on binge eating disorder. Braz J Psychiatry. 2011;33(Suppl 1):S81-108.

96. Poli R, Maninetti L, Bodini P, Agrimi E. Obesity, binge eating, obstruction sleep apnea and psychopathological features. Clin Neuropsychiatry. 2012;9:166-71.

97. Utter J, Neumark-Sztainer D, Wall M, Story M. Reading magazine articles about dieting and associated weight control behaviors among adolescents. J Adolesc Health. 2003;32:78-82.

98. Hudson JI, Lalonde JK, Berry JM, Pindyck LJ, Bulik CM, Crow SJ, et al. Bingeeating disorder as a distinct familial phenotype in obese individuals. Arch Gen Psychiatry. 2006:63:313-9.

99. Javaras KN, Laird NM, Reichborn-Kjennerud T, Bulik CM, Pope HG Jr, Hudson J. Familiality and heritability of binge eating disorder: results of a casecontrol family study and a twin study. Int J Eat Disord. 2008;41:174-9.

100. Trace SE, Baker JH, Peñas-Lledó E, Bulik CM. The genetics of eating disorders. Annu Rev Clin Psychol. 2013;9:589-620.

\section{Publisher's Note}

Springer Nature remains neutral with regard to jurisdictional claims in published maps and institutional affiliations. 